\title{
Contemporary diagnosis of venous malformation
}

This article was published in the following Dove Press journal:

Journal of Vascular Diagnostics

14 November 2013

Number of times this article has been viewed

BB Lee'

\section{Baumgartner ${ }^{2}$}

'Department of Surgery, George Washington University, Washington, DC, USA; ${ }^{2}$ Swiss Cardiovascular Center, University Hospital Bern, Bern, Switzerland
Correspondence: BB Lee Department of Surgery, George Washington University, Washington, DC, USA Email bblee38@comcast.net
Abstract: Venous malformation is a congenital vascular malformation resulting from defective development during various stages of embryogenesis and selectively affecting the venous system. Depending on the embryologic stage when the developmental arrest occurred, the clinical presentation of venous malformation is extremely variable in location, extent, severity, natural progression, and hemodynamic impact. Extratruncular lesions occur in the earlier stages of embryonic life, and retain characteristics unique to mesenchymal cells (angioblasts), growing and proliferating when stimulated internally (eg, by menarche, pregnancy, and hormones) or externally (eg, by trauma or surgery). These lesions also have a significant hemodynamic impact on the venous system involved, in addition to the risk of localized intravascular coagulopathy. However, truncal lesions, as defective developments along the late stage, no longer carry the risk of proliferation and recurrence due to lack of mesenchymal characteristics. Although, they often have serious hemodynamic consequences due to direct involvement of the main vein trunk. Therefore, a thorough clinical history and careful physical examination should be followed by an appropriate combination of noninvasive and less invasive tests (eg, Doppler ultrasonography, magnetic resonance imaging, computed tomography) to confirm the clinical impression as well as to define the extent and severity of the venous malformation. Invasive tests, eg, phlebography or angiography, are seldom needed for the diagnosis per se. Additional evaluation for coagulation abnormalities, eg, D-dimer and fibrinogen levels, is generally recommended, especially for the treatment of surgery and endovascular candidates with extensive lesions to assess the localized intravascular coagulopathy status. Localized intravascular coagulopathy may cause serious thrombohemorrhagic events, including deep venous thrombosis and pulmonary embolism.

Keywords: venous malformation, extratruncular lesions, truncal lesions, noninvasive tests, less invasive tests, localized intravascular coagulopathy

\section{Introduction}

Venous malformation is a congenital vascular malformation arising from defective development during various stages of embryogenesis selectively affecting the venous system. ${ }^{1-4}$ Venous malformation is often erroneously called "hemangioma", resulting in potentially serious mistakes in management. Indeed, during the last century, when there was insufficient knowledge about the condition, venous malformation (VM) was called hemangioma based on limited experience regarding vascular malformations and the fact that a rational classification concept was not established. Unfortunately, VM is still mistakenly described as "cystic/cavernous hemangioma" by physicians who are not familiar with the current terminology and literature..$^{5-7}$ 
Venous malformations and neonatal or infantile hemangioma ${ }^{8-12}$ are as different as an apple and an orange. Hemangioma is a vascular tumor and not a congenital vascular malformation. Although congenital vascular malformations and hemangioma were classified together as "vascular anomalies" by the International Society for the Study of Vascular Anomalies classification ${ }^{13,14}$ to represent the entire group of anomalous vascular disorders, they are different not only in pathogenesis but also in clinical behavior.

Hemangioma originate from endothelial cells and have a distinct growth cycle characterized by a proliferation phase of early rapid growth followed by an involutional phase of slow regression. Unlike congenital vascular malformations, hemangiomas usually appear during the early neonatal period in perfectly normal neonates, but undergo self-limited growth and subsequent involution which is usually complete before the age of 5-10 years in the majority of cases (Figure 1).

In contrast, congenital VM and congenital vascular malformations in general ${ }^{15-18}$ exist at birth as an inborn error, although clinically not always obvious initially. The embryonic tissue remnants originate from the early stage of embryogenesis, never go away, but remain through the rest of life and
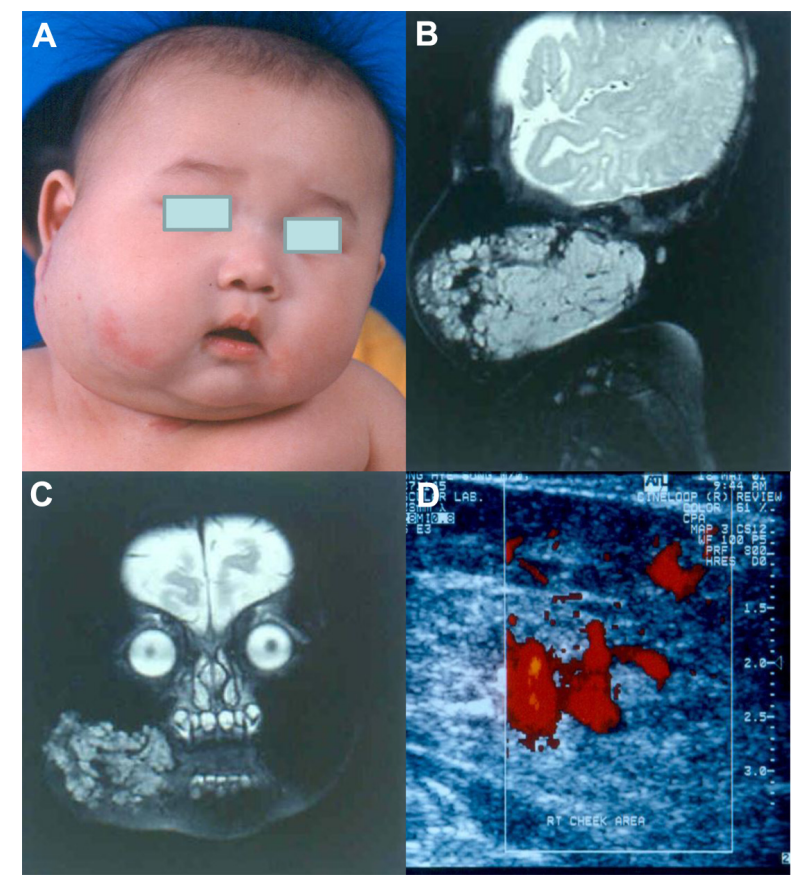

Figure I (A) Infantile hemangioma seen as a rapidly expanding lesion along the right cheek, first noted a few months after birth, which could be mistaken for a venous malformation. (B and $\mathbf{C}$ ) Typical findings on magnetic resonance imaging of (infantile) hemangioma affecting the right cheek with prominent vascularity that helps differentiate it from a common vascular malformation. (D) Duplex ultrasonographic findings of active/high blood flow through the lesion in contrast with what would be found with a vascular malformation lesion.

Note: Copyright (C) 2007. Phlebology. Lee BB, Laredo J, Lee TS, Huh S, Neville R. Terminology and classification of congenital vascular malformations. Phlebology. 2007;22(6):249-252. ${ }^{7}$ maintain self-perpetual growth potential as an embryologic characteristic among the extratruncular lesions.

Depending on the embryologic stage when the developmental arrest has occurred, the clinical presentation of VM is extremely variable in location, extent, severity, and natural progress in addition to the hemodynamic impact (eg, marginal vein). ${ }^{19-22}$ Hence, diagnostics in patients with suspected VM mandate a proper understanding of embryologic and hemodynamic characteristics as well as adequate classification as one of many different congenital vascular malformations.

\section{Definition and classification}

Venous malformation, as one of the most common congenital vascular malformations, has been a source of confusion, with numerous names, including cavernous hemangioma, cavernous angioma, and phlebangioma. Many names have been based on the appearance of the anomaly, its anatomy, and its pathology, while other names have come from the clinicians who first described the lesion (eg, Klippel-Trenaunay syndrome), often resulting in redundant and confusing terminology. ${ }^{23-26}$ Today, VMs are defined according to the Hamburg classification as part of a large group of congenital vascular malformations, together with arterial, capillary, and lymphatic malformations (Table 1).

Table I Hamburg classification* for types and embryologic subtypes of congenital vascular malformation

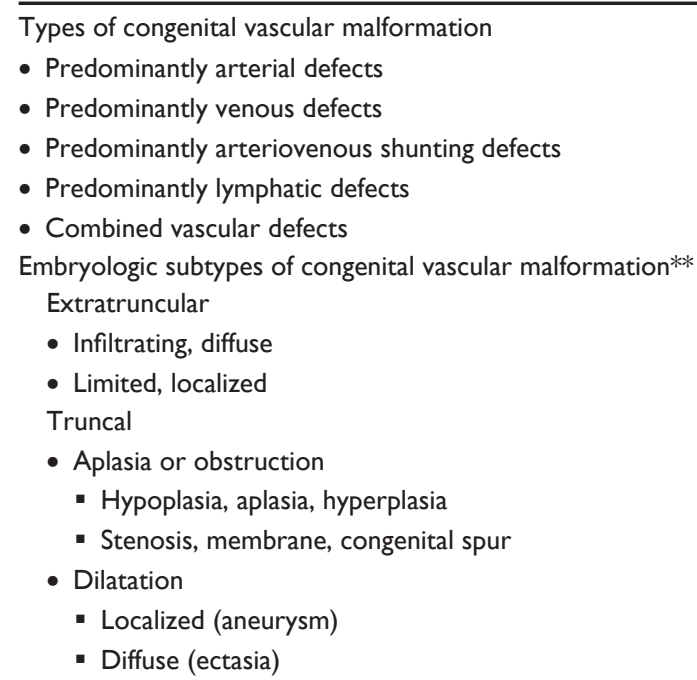

Notes: Classification based on consensus regarding congenital vascular malformation reached at an International Workshop held in Hamburg, Germany, 1988, and subsequently modified. Capillary malformation is not included. *Both types may exist together, and may be combined with various other malformations (eg, capillary, arterial, arteriovenous shunting, venous, hemolymphatic, and/or lymphatic) and/or exist with hemangioma; **developmental arrest at different stages of embryonic life (earlier stage, extratruncular form; later stage, truncal form). 
Venous malformations are a result of defective development of the venous system during the two distinctly different stages of embryogenesis, and are further classified based on the embryologic stage when it developed, ie, extratruncular lesions (immature vascular network) and truncal lesions (mature vascular network). ${ }^{27-34}$

\section{Extratruncular VM lesions}

Extratruncular VM lesions (Table 1) are the outcome of defective development in earlier embryonic life when the vascular system is in the reticular stage before the main vascular trunks are formed. Therefore, these pretruncal embryonic lesions never involve the main trunk of the formed vein itself but remain as an independent "no-name" vascular structure separate from mature veins.

Extratruncular lesions retain unique characteristics of mesenchymal cells (angioblasts) as embryonic tissue remnants of mesodermal origin. They retain their potential to grow and proliferate when stimulated internally (eg, menarche, pregnancy, and hormones) or externally (eg, trauma, surgery). Hence, these lesions respond to various stimuli and proliferate, carrying a high risk of recurrence following incomplete treatment. Natural growth is usually slow and proportionate to the person's growth, and there is no spontaneous regression, as in hemangiomas. ${ }^{27-34}$

Depending on lesion size and location, VM lesions have a significant hemodynamic impact on the venous system involved, in addition to the risk of localized intravascular coagulopathy (LIC). Extratruncular VMs are further subdivided into diffuse infiltrating lesions and localized limited lesions to direct clinical management better. Diffuse infiltrating extratruncular VMs often cause symptoms due to compression of the surrounding structures, including muscles and nerves (Figure 2).

\section{Truncal VM lesions}

Truncal VM lesions (Table 1) occur as defective development long after the primitive reticular stage of vascular development. Because the defective development occurs during the late stage when the vascular trunk is formed, these "posttruncal fetal lesions" no longer carry a risk of proliferation and recurrence due to lack of mesenchymal characteristics.

These lesions often have serious hemodynamic consequences due to direct involvement of the main vein trunk. In other words, all truncal lesions involve "named" vein trunks, eg, femoral, popliteal, and iliac veins. Truncal VM lesions manifest clinically as a defective main (or named) vein. Presentation ranges from incomplete or immature lesions (aplasia or hypoplasia) ${ }^{35-37}$ to overdeveloped lesions (hyperplasia or aneurysm) ${ }^{38-40}$ directly affecting the main axial veins in contrast with extratruncular lesions. ${ }^{27-34}$ Truncal lesions are further subdivided into obstructive ${ }^{41-44}$ or dilated ${ }^{45-47}$ lesion types.

Avalvulia or avalvulosis (meaning absence of valves) is another form of congenital venous hypoplasia that produces venous reflux. Together with atresia of the lumens of venous trunks and venous aneurysms, these conditions are relatively common VMs. Another unique form of truncal VM is a fetal
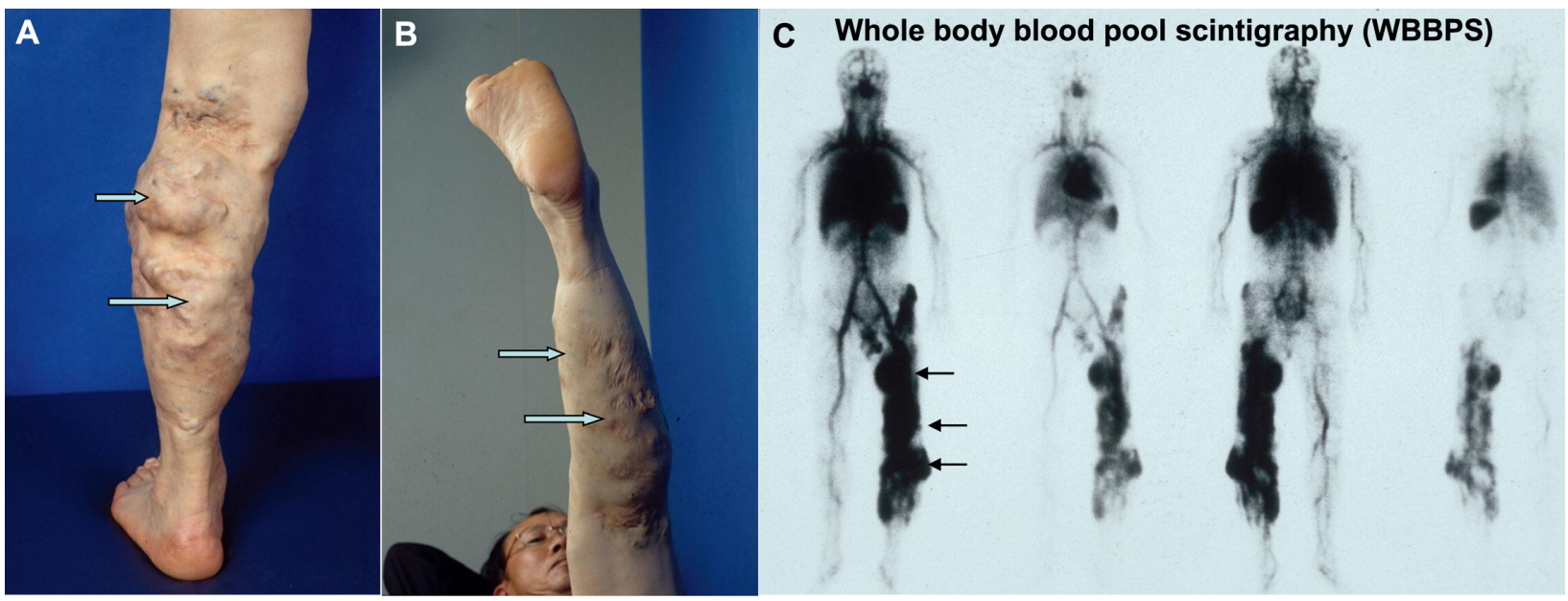

Figure 2 (A) VM affecting the entire left lower extremity with significant symptoms. It is a diffuse infiltrating extratruncular lesion possessing mesenchymal cell characteristics of steady growth. (B) Spontaneous collapse of the VM lesion when the leg is elevated. This is typical of a pure VM, and is a significant clue to support its nature as predominantly a VM in contrast with other kinds of congenital vascular malformations. (C) Positive evidence of abnormal blood pooling along the lesion on whole body blood pool scintigraphy, confirming the lesion as a VM.

Note: Copyright (c) 2007. Phlebology. Lee BB, Laredo J, Lee TS, Huh S, Neville R. Terminology and classification of congenital vascular malformations. Phlebology. 2007;22(6):249-252. ${ }^{7}$

Abbreviation: VM, venous malformation. 
remnant (truncal) vessel as a persistent, large, embryonic vein, such as the marginal vein or the sciatic vein when a fetal (truncal) vessel fails to undergo normal involution. ${ }^{48-52}$

Because these persistent fetal truncal vein remnants show no venous valves and the embryonic veins can be large, there is an associated risk of venous thromboembolism, especially when the condition is combined with consumptive coagulopathy, which is a common phenomenon with both extratruncular and truncal VMs (eg, the marginal vein, Figure 3).
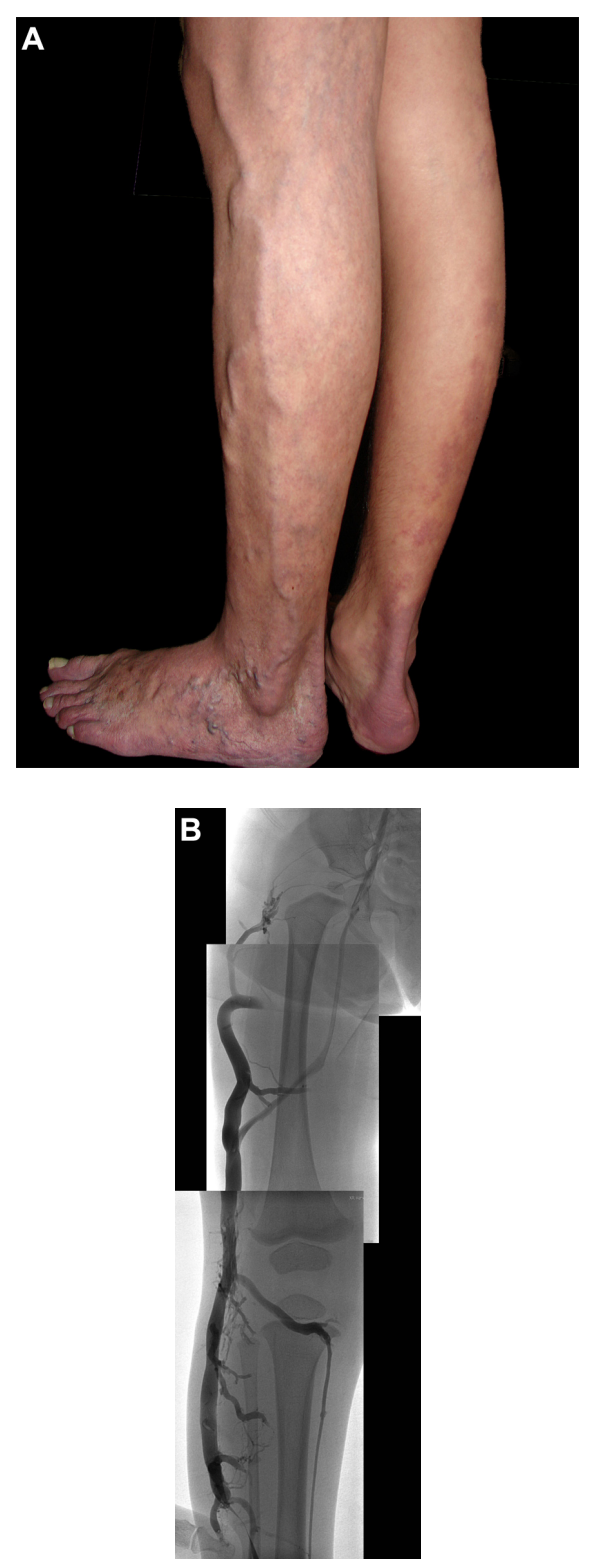

Figure 3 (A) Clinical finding of a marginal/lateral embryonic vein along the lateral aspect of the left lower extremity. This unique vein structure is a persistent fetal remnant vessel following failure of normal involution/regression. (B) Angiographic finding for this marginal vein, which remains the only major venous drainage route for this patient, with a lack of normal development of the deep venous system. Therefore, surgical excision to control venous hypertension is contraindicated. Note: Copyright (C) 2012. Phlebolymphology. Lee BB. Venous embryology: the key to understanding anomalous venous conditions. Phlebolymphology. 2012;19(4):170-181. ${ }^{20}$

\section{Clinical evaluation}

When VM lesions are present in superficial areas as localized bluish or purple lesions on the skin and mucosa, clinical examination is generally sufficient to make a correct clinical diagnosis. When present in a deep anatomic location, tissue, or organ, especially when asymptomatic, it is difficult to make a correct diagnosis by clinical examination alone.

The majority of VMs present with swelling and pain as the most common clinical findings and give a clue for further examination, and phleboliths detected on the plain soft tissue $\mathrm{X}$-ray are a particularly good clue for VM with intraluminal venous stasis and subsequent thrombosis. Occasionally direct puncture needle aspiration of the lesion confirms the VM with the venous blood or rules it out with clear fluid/ lymph. Diagnosis of VM is not always easy, because it can mimic other congenital vascular malformations and even some malignant tumors. ${ }^{53,54}$

For proper clinical evaluation, a thorough clinical history is necessary as the first step in diagnostic evaluation because VM is one of a number of congenital vascular malformation lesions that can arise as a birth defect. Evaluation should include detailed information on presence of the lesion at birth, any subsequent change during life, triggers for rapid change such as puberty or trauma, and family history.

Appropriate physical examination should include careful assessment (inspection, palpation, auscultation) of both the arterial and venous systems, including a detailed pulse examination. Thorough inspection of the lesion, including the leg elevation shown in Figure 2B, should include evaluation for color, appearance, size, distribution, and localization of the lesion(s), as well as consistency on palpation and temperature (Figure 2). Any edema, skin changes, varicosities, induration, pigmentation, thrombophlebitis, or ulceration suggestive of chronic venous insufficiency should be documented properly.

Physical examination should include detection of an enlarged or longer extremity, digital anomalies, and asymmetric growth of any part of the body. Pain (spontaneous or provoked) and tenderness should be assessed with proper documentation, in addition to auscultation for a possible bruit along the lesions.

Many VM lesions are associated with other congenital vascular malformations, especially lymphatic malformations. Therefore, special attention to cellulitis and lymphangitis is required during examination. VM with pelvic involvement may be associated with hematuria and rectal bleeding (Figure 4). The appropriate combination of noninvasive 


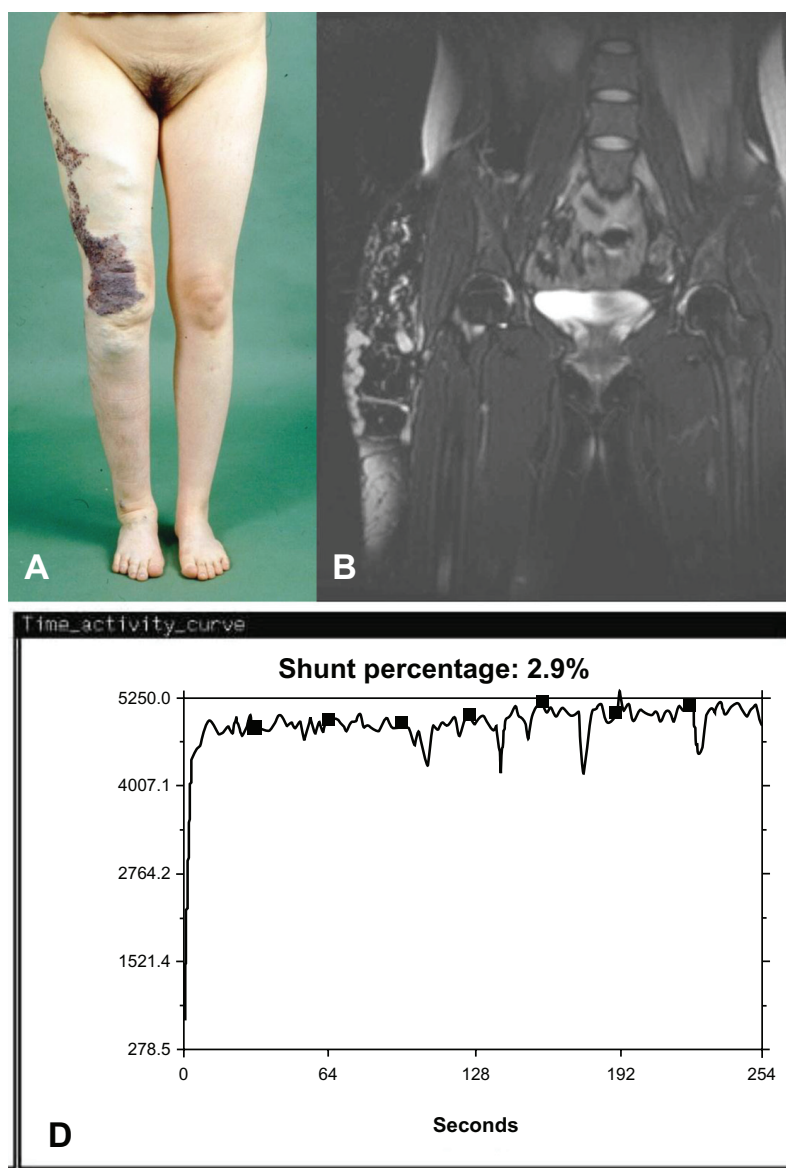

TLPS (transarterial lung perfusion scintigraphy)
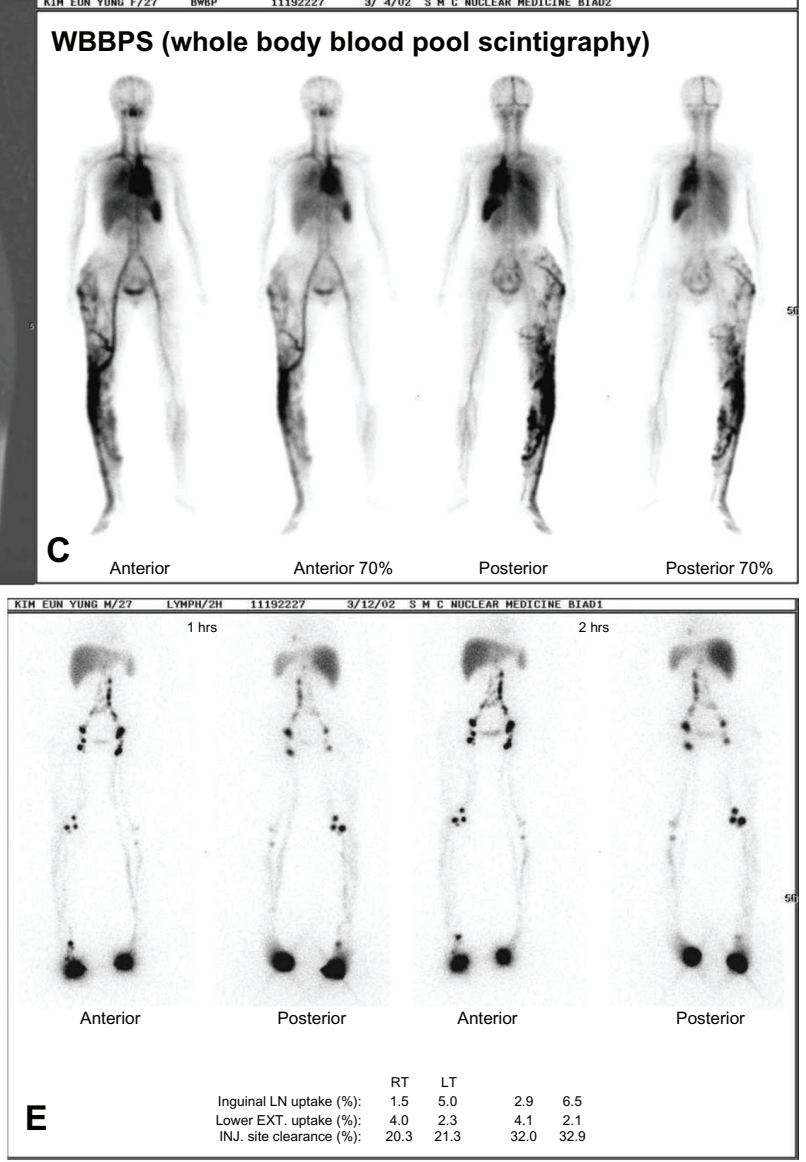

Radionuclide lymphoscintigraphy

Figure 4 (A) Clinical appearance of VM lesion affecting the right lower extremity as a hemolymphatic malformation, mixed with lymphatic malformation and capillary malformation, often known as Klippel-Trenaunay syndrome. (B) Finding on magnetic resonance imaging of extratruncular VM lesion diffusely infiltrating into the soft tissue and muscles of the right lower extremity. (C) Findings on whole body blood pool scintigraphy of a massive abnormal blood pool throughout the entire right lower extremity and effective ruling out of any additional lesions in the rest of the body. (D) Transarterial lung perfusion scintigraphy study negative for abnormal arteriovenous shunting ( $2.9 \%$ is within the normal range). (E) Findings on radionuclide lymphoscintigraphy of an anatomically normal but functionally abnormal double (deep and superficial) lymphatic transporting vessel, visualized along the right lower extremity. This finding is consistent with the clinical finding of chronic lymphedema secondary to hypoplasia of the superficial lymphatic system which is well compensated by the deep system.

Note: Copyright @ 2007. Phlebology. Lee BB, Laredo J, Lee TS, Huh S, Neville R. Terminology and classification of congenital vascular malformations. Phlebology. 2007;22(6):249-252. ${ }^{7}$ Abbreviations: VM, venous malformation; LN, lymph nodes; RT, right; LT, left.

and less invasive tests should follow in order to confirm the clinical impression as well as to define the extent and severity of the VM. ${ }^{55-61}$

\section{Noninvasive vascular investigations}

Evaluation of VMs for diagnosis per se can be done in the majority of cases using noninvasive tests alone. Invasive tests can be reserved until needed as a road map for when treatment is performed.

\section{Doppler ultrasonography}

Doppler ultrasonography ${ }^{1,62-65}$ remains the first step in evaluation of the hemodynamic status of any congenital vascular malformation and easily confirms the VM as a "slow flow" lesion. Doppler ultrasonography can also be helpful to distinguish the affected vessel type as being a slow flow malformation and differentiating between venous and lymphatic lesions.

VMs in subcutaneous or intramuscular tissues present as compressible hypoechogenic or anechogenic vascular spaces on B-mode ultrasound, while spectral Doppler demonstrates low flow status. Thrombosed lesions appear to be partially compressible or not compressible. Such features would allow correct differentiation of VMs from lymphatic malformations, which appear as noncompressible cystic spaces or arteriovenous malformations that demonstrate high flow. However, Doppler ultrasonography has a limited ability to assess involvement of adjacent structures, such as nerves and bone, and is less helpful in defining the extent of lesions not located in the extremities. Assessment of the feeding and draining vessels is best obtained by venography and/or varicography. 


\section{Magnetic resonance imaging}

Together with Doppler ultrasonography, magnetic resonance imaging (MRI) ${ }^{1,66-69}$ is the gold standard noninvasive diagnostic test for evaluation of VM lesions to verify the extent of the lesion. T2-weighted magnetic resonance images with and without contrast are not only able to confirm the nature of a congenital vascular malformation lesion such as VM with high signal intensity but are also able to provide detailed information on its extent and severity, in addition to its relationship with adjacent or underlying tissues. Phleboliths as a hallmark of VM lesions appear as low-signal or void on T1-weighted and T2-weighted MRI images (Figure 4).

Initial assessment of the VM using MRI (fat saturated T2-weighted imaging) with no contrast is now fully accepted as a routine part of the initial investigation. MRI with no contrast is recommended for follow-up assessment of natural progression as well as to monitor the therapeutic response, at mean 2-3-year intervals unless otherwise indicated.

MRI with contrast (angiography and venography) is indicated to differentiate mixed conditions of VM and lymphatic malformation. Magnetic resonance venography may be more helpful for assessment of the therapeutic outcome in complex forms of VM, and may be most helpful for assessment of the entire infradiaphragmatic venous system altogether at the same time.

\section{Computed axial tomography}

Advanced computed tomography (CT) diagnostics can provide more information on congenital vascular malformations than MRI, especially when the test is combined with contrast. Newly developed 64-slice spiral CT angiography can visualize the extent of a VM lesion, and the relationship with adjacent vessel, muscle, and bone structures more clearly from multiple angles in three dimensions..$^{70-73}$

Additional information on the skeletal system together with the soft tissue is more advantageous than standard MRI. However, arteriovenous malformations will get the most benefit from CT angiography with three-dimensional reconstruction regarding the extent of the lesion and its relationship with surrounding structures. CT angiography is valuable for assessment of complicated congenital vascular malformations, especially postoperative or postexcisional recurrence.

\section{Whole body blood pool scintigraphy}

Whole body blood pool scintigraphy ${ }^{74-77}$ is an optional test for diagnosis of VM in general, and excellent when screening for further VM lesions because it is able to detect $1.0 \mathrm{~mL}$ of abnormal blood pooling throughout the body. Therefore, whole body blood pool scintigraphy is the safest, easiest, and cheapest method for general assessment of VM (multifocal lesions), for follow-up assessment after therapy sessions, as well as follow-up of the natural course. This technique is also excellent for ruling out a lymphatic malformation that is sometimes hard to differentiate based on MRI alone (Figure 4).

\section{Transarterial lung perfusion scintigraphy}

Transarterial lung perfusion scintigraphy ${ }^{1,13,78}$ is also one of the optional tests and the most accurate way of assessing arteriovenous malformations located along an extremity, and is sensitive enough to detect microfistulous shunting that arteriography might fail to detect (eg, a microshunting arteriovenous malformation). Therefore, transarterial lung perfusion scintigraphy remains a crucial test either to rule out a hidden microfistulous arteriovenous malformation as part of Parkes-Weber syndrome or to confirm the condition as Klippel-Trenaunay syndrome by ruling out hidden arteriovenous malformations ${ }^{79-81}$ (Figure 4). Because of the need for cumbersome arterial puncture, its clinical use in VM diagnostics has been limited to specific indications.

\section{Radionuclide lymphoscintigraphy}

Radionuclide lymphoscintigraphy ${ }^{82-85}$ has a limited role in the diagnosis of VM, but is the only specific test for assessment of the lymphatic system, and remains essential to confirm as well as assess the extent of truncal lymphatic malformation involved in Klippel-Trenaunay syndrome as primary lymphedema together with VM lesions. ${ }^{86-89}$ Therefore, it is a mandatory test for hemolymphatic malformation, ${ }^{1,13}$ a combined form of VM, for assessment of lymphatic function. Interpretation of the results should be extended from clearance rate to the general status of lymph vessels and nodes, including dermal backflow (Figure 4).

\section{Conventional soft tissue plain radiography}

The standard plain X-ray remains essential in the management of VM to assess for phleboliths as a possible cause of aching and/or pain. It remains useful for identifying abnormalities in the soft tissue and malformation-related abnormalities in the skeletal system other than phleboliths. ${ }^{90,91}$ It is routinely indicated for assessment of adjacent skeletal anomalies and overgrowth, eg, vascular bone syndrome, especially in patients with Klippel-Trenaunay syndrome, and confirmation of phleboliths as extra evidence of coagulopathy in VM lesions. ${ }^{92,93}$ 


\section{Bone scanography}

Scanograms are long bone radiographs that provide an accurate measurement of long bone length. This test is essential when assessing for any discrepancy in bone length involving the upper or lower limbs. Therefore, any VM or congenital vascular malformation combining abnormal long bone growth with a discrepancy in leg/arm length should have a baseline scanographic measurement repeated every two years until bone growth is complete. The assessment should be extended to include evaluation for pelvic tilt and compensatory scoliosis. Documentation of this would become an objective criterion for further management. ${ }^{94,95}$

Other noninvasive studies, such as plethysmography, segmental pressure measurement, and pulse volume recordings can be used selectively based on clinical correlations with the abnormal findings (eg, outflow obstruction) which need to be assessed.

\section{Invasive vascular tests}

Invasive tests ${ }^{1,13,96,97}$ are seldom needed to establish the diagnosis of VM and can be deferred until intervention is required. Conventional venography and/or percutaneous direct puncture phlebography are generally indicated for planning of treatment, which may be surgical or endovascular. However, invasive tests may be required for diagnosis when noninvasive tests (eg, CT and/or MRI) fail to confirm the diagnosis or delineate important diagnostic details. These tests include: ascending, descending, and/or segmental venography or phlebography; standard and/or selective arteriography; percutaneous direct puncture angiography, ie, arteriography or phlebography; and varicography or lymphography.

Ascending phlebography with or without application of a compression bandage is needed as a part of the road map when therapy is indicated for $\mathrm{VM}$ lesions affecting the lower extremity. When combined with intravenous ultrasonography, more precise anatomic information can be provided for an obstructive truncal VM lesion along the iliac vein, ie, the exact dimensions of venous obstructions or aneurysms.

Descending phlebography with or without the Valsalva test is indispensable for truncal VM with chronic venous insufficiency to assess for deep venous reflux along the pelvic veins and/or sciatic veins. These studies are often required as a road map for subsequent embolo/sclerotherapy.

Direct puncture percutaneous phlebography is indicated for all extratruncular VM lesions as a road map for treatment to verify the size and extent of the lesion together with the status of draining veins. It is quite useful for identifying large draining veins from $\mathrm{VM}$ lesions for subsequent embolo/sclerotherapy with a reduced risk of recurrence (Figure 3B).

\section{VM and coagulopathy}

Coagulation abnormalities are common in patients with VM lesions (42\%) especially in those with extensive lesions involving a large surface area and deep tissue structures. Coagulation abnormalities occurring in VMs are due to LIC $^{9-101}$ and are different from those seen in KasabachMerritt syndrome. ${ }^{102-105}$ Kasabach-Merritt syndrome, which develops only in the hemangioma/vascular tumor, is a hallmark of coagulopathy. It is initiated by platelet trapping within a vascular tumor that develops in infancy. However, LIC associated with the VM lesion is a distinctive, lifelong consumptive coagulopathy precipitated by blood stagnation within the VM lesion resulting in thrombosis and subsequent phlebolith formation. Therefore, palpable phleboliths and an elevated D-dimer level remain the hallmarks of LIC in patients with VM.

LIC is characterized by a decrease in fibrinogen, an increase in D-dimer levels, and the presence of soluble fibrin complexes. Platelet counts are normal or slightly decreased, but generally accompanies mild reduction of the platelet count due to the increased consumption. LIC is more likely associated with large and/or deep VM lesions of any location and may present with palpable phleboliths on examination. These patients are often found to have elevated D-dimer levels combined with low fibrinogen levels and commonly present with a VM lesion involving an extremity.

LIC may cause serious thrombohemorrhagic events, including deep venous thrombosis and pulmonary embolism. LIC can also cause disseminated intravascular coagulopathy with life-threatening hemorrhage. A number of events, including sclerotherapy, surgical resection, bone fracture, prolonged immobilization, pregnancy, and menstruation are known to trigger the conversion of LIC to disseminated intravascular coagulopathy, with bleeding related to factor consumption and multiorgan failure related to disseminated microvascular thrombosis. ${ }^{103,106-109}$

Clinical symptoms associated with worsening of LIC are pain, thrombosis, and bleeding at wound sites during surgery. In severe forms, bleeding can occur, causing painful hematomas within the VM, hemarthrosis in patients with joint involvement, or bleeding outside the area of the VM. ${ }^{103}$

Patients with extensive VMs or high-risk lesions should undergo the following laboratory tests: a full blood count including hemoglobin levels and platelet count; a quantitative 
D-dimer assay; fibrinogen level; and prothrombin time, activated partial thromboplastin time, and coagulation profile (optional). Measurement of hemoglobin and platelet counts are especially recommended to exclude chronic blood loss from VMs involving the gastrointestinal tract.

It is important to obtain an accurate diagnostic algorithm for coagulopathies associated with VM to guide appropriate management of these potentially life-threatening disorders. Measurement of D-dimer and fibrinogen levels should be included in the baseline laboratory evaluation of all patients with VM.

\section{Histopathology}

A biopsy should be performed whenever diagnosis remains doubtful for the differential diagnosis with malignant tumor in particular besides a noninvoluting vascular tumor such as a noninvoluting congenital hemangioma level. ${ }^{110-112}$ These lesions have high flow on Doppler and persist indefinitely, and may be confused with an arteriovenous malformation. Conclusive genetic tests can be useful to assess rare inherited forms of VM.

\section{Disclosure}

The authors report no conflicts of interest in this work.

\section{References}

1. Lee BB, Bergan J, Gloviczki P, et al. Diagnosis and treatment of venous malformations: Consensus Document of the International Union of Phlebology, 2009. Int Angiol. 2009;28:434-451.

2. Lee BB, Bergan J. Transition from alcohol to foam sclerotherapy for localized venous malformation with high risk. In: Bergan J, Le Cheng V, editors. A Textbook Foam Sclerotherapy. London, UK: The Royal Society of Medicine Press Ltd; 2008.

3. Lee BB, Kim DI, Huh S, et al. New experiences with absolute ethanol sclerotherapy in the management of a complex form of congenital venous malformation. J Vasc Surg. 2001;33:764-772.

4. Lee BB, Do YS, Byun HS, Choo IW, Kim DI, Huh SH. Advanced management of venous malformation (VM) with ethanol sclerotherapy: mid-term results. J Vasc Surg. 2003;37:533-538.

5. Lee BB, Laredo J. Hemangioma and venous/vascular malformation are different as an apple and orange! Acta Phlebologica. 2012;13:1-3.

6. Lee BB. Venous malformation is not a hemangioma. Flebologia Y Linfologia Lecturas Vasculares. 2012;7:1021-1023.

7. Lee BB, Laredo J, Lee TS, Huh S, Neville R. Terminology and classification of congenital vascular malformations. Phlebology. 2007;22:249-252.

8. Mulliken JB, Glowacki J. Hemangiomas and vascular malformations in infants and children: a classification based on endothelial characteristics. Plast Reconstr Surg. 1982;69:412-422.

9. Mulliken JB. Treatment of hemangiomas. In: Mulliken JB, Young AE, editors. Vascular Birthmarks, Hemangiomas and Malformations. Philadelphia, PA: WB Saunders; 1988.

10. Mulliken JB, Zetter BR, Folkman J. In vivo characteristics of endothelium from hemangiomas and vascular malformations. Surgery. 1982;92: 348-353.

11. Mulliken JB. Cutaneous vascular anomalies. Semin Vasc Surg. 1993;6:204-218.
12. Enjolras O, Riche MC, Merland JJ, Escandej P. Management of alarming hemangiomas in infancy: a review of 25 cases. Pediatrics. 1990;85:491-498.

13. Lee BB, Baumgartner I, Berlien HP, et al. Consensus Document of the International Union of Angiology (IUA)-2013. Current concept on the management of arterio-venous management. Int Angiol. 2013;32: 9-36.

14. Mulliken JB. Classification of vascular birthmarks. In: Mulliken JB, Young AE, editors. Vascular Birthmarks: Hemangiomas and Malformations. Philadelphia, PA: WB Saunders; 1988.

15. Lee BB, Bergan JJ. Advanced management of congenital vascular malformations: a multidisciplinary approach. J Cardiovasc Surg. 2002;10: 523-533.

16. Lee BB. Critical issues on the management of congenital vascular malformation. Ann Vasc Surg. 2004;18:380-392.

17. Lee BB, Mattassi R, Loose D, Yakes W, Tasnadi G, Kim HH. Consensus on controversial issues in contemporary diagnosis and management of congenital vascular malformation - Seoul communication. Int J Angiol . 2004; $13: 182-192$

18. Lee BB, Villavicencio L. Arteriovenous anomalies. In: Cronenwett JL, Johnston KW, editors. Rutherford's Vascular Surgery. 7th ed. Philadelphia, PA: Saunders Elsevier; 2010.

19. Lee BB, Laredo J, Neville R. Embryological background of truncular venous malformation in the extracranial venous pathways as the cause of chronic cerebrospinal venous insufficiency. Int Angiol. 2010;29: 95-108.

20. Lee BB. Venous embryology: the key to understanding anomalous venous conditions. Phlebolymphology. 2012;19:170-181.

21. Lee BB, Laredo J, Lee SJ, Huh SH, Joe JH, Neville R. Congenital vascular malformations: general diagnostic principles. Phlebology. 2007;22:253-257

22. Lee BB. Venous malformation and haemangioma: differential diagnosis, diagnosis, natural history and consequences. Phlebology. 2013;28 Suppl 1:176-187.

23. Malan E, Puglionisi A. Congenital angiodysplasias of the extremities, note II: arterial, arterial and venous, and hemolymphatic dysplasias. J Cardiovasc Surg (Torino). 1965;6:255-345.

24. Malan E, Puglionisi A. Congenital angiodysplasia of the extremities. J Cardiol Surg. 1964;5:87-130.

25. Villavicencio JL. Congenital vascular malformations: historical background. Special issue. Phlebology. 2007;22:247-248.

26. Malan E. History and nosography. In: Malan E, editor. Vascular Malformations (Angiodysplasias). Milan, Italy: Carlo Erba Foundation; 1974.

27. Vollmar J, Vogt K. Angiodysplasia and the skeletal system. Der Chirurg. 1976;47:205-213. German.

28. Belov ST. Classification of congenital vascular defects. Int Angiol. 1990;9:141-146.

29. Belov S. Classification, terminology, and nosology of congenital vascular defects. In: Belov S, Loose DA, Weber J, editors. Vascular Malformations. Reinbek, Germany: Einhorn-Presse; 1989.

30. Belov ST. Anatomopathological classification of congenital vascular defects. Semin Vasc Surg. 1993;6:219-224.

31. Leu HJ. Pathomorphology of vascular malformations: analysis of 310 cases. Int Angiol. 1990;9:147-155.

32. DeTakats G. Vascular anomalies of the extremities. Surg Gynecol Obstet. 1932;55:227-237.

33. Bastide G, Lefebvre D. Anatomy and organogenesis and vascular malformations. In: Belov ST, Loose DA, Weber J, editors. Vascular Malformations. Reinbek, Germany: Einhorn-Presse Verlag; 1989.

34. Woolard HH. The development of the principal arterial stems in the forelimb of the pig. Contrib Embryol. 1922;14:139-154.

35. Zamboni P, Pisano L, Mari C, Galeotti R, Feo C, Liboni A. Membranous obstruction of the inferior vena cava and Budd-Chiari syndrome. Report of a case. J Cardiovasc Surg (Torino). 1996;37:583-587.

36. Nedelmann M, Kaps M, Mueller-Forell W. Venous obstruction and jugular valve insufficiency in idiopathic intracranial hypertension. J Neurol. 2009;256:964-969. 
37. Lee BB, Laredo J, Deaton D, Neville R. Endovascular management of Budd-Chiari syndrome - suprahepatic inferior vena cava occlusive disease. In: Heuser RR, Henry M, editors. Textbook of Peripheral Vascular Interventions. 2nd ed. London, UK: Informa Healthcare, Informa UK Ltd; 2008.

38. Kersting S, Rössel T, Hinterseher I, et al. Isolated aneurysm of the internal jugular vein. Vasa. 2008;37:371-373.

39. Ilijevski NS, Radak S, Novakovic B, Miholjcic A, Radak D. Images in vascular medicine. Jugular vein aneurysm - ultrasonographic evaluation. Vasc Med. 2006;11:51.

40. Fishman G, DeRowe A, Singhal V. Congenital internal and external jugular venous aneurysms in a child. Br J Plast Surg. 2004;57: 165-167.

41. Eifert S, Villavicencio JL, Kao TC, Taute BM, Rich NM. Prevalence of deep venous anomalies in congenital vascular malformations of venous predominance. J Vasc Surg. 2000;31:462-471.

42. Belov ST. Congenital agenesis of the deep veins of the lower extremity: surgical treatment. J Cardiovasc Surg. 1972;13:594.

43. Raju S, Hollis K, Neglen P. Obstructive lesions of the inferior vena cava: clinical features and endovenous treatment. J Vasc Surg. 2006;44:820.

44. Lee BB, Villavicencio L, Kim YW, et al. Primary Budd-Chiari syndrome: outcome of endovascular management for suprahepatic venous obstruction. J Vasc Surg. 2006;43:101-110.

45. Gillespie DL, Villavicencio JL, Gallagher C, et al. Presentation and management of venous aneurysms. J Vasc Surg. 1997;26:845-852.

46. Zamboni P, Cossu A, Carpanese L, Simonetti G, Massarelli G, Liboni A. The so-called venous aneurysms. Phlebology. 1990;5:45-50.

47. Friedman SG, Krishnasastry KV, Doscher W, Deckoff SL. Primary venous aneurysms. Surgery. 1990;108:92-95.

48. Vollmar J, Voss. Vena marginalis lateralis persistens - the forgotten vein of the angiologists. Vasa. 1979;8:192-202. German.

49. Lee BB. Venous embryology: the key to understanding anomalous venous conditions. Phlebolymphology. 2012;19:170-181.

50. Kim YW, Lee BB, Cho JH, Do YS, Kim DI, Kim ES. Haemodynamic and clinical assessment of lateral marginal vein excision in patients with a predominantly venous malformation of the lower extremity. Eur $J$ Vasc Endovasc Surg. 2007;33:122-127.

51. Mattassi R. Approach to marginal vein: current issue. Phlebology. 2007;22:283-286

52. Weber J, Daffinger N. Congenital vascular malformations: the persistence of marginal and embryonal veins. Vasa. 2006;35:67-77.

53. Boon LM, Fishman SJ, Lund DP, Mulliken JB. Congenital fibrosarcoma masquerading as congenital hemangioma: report of two cases J Pediatr Surg. 1995;30;1378-1381.

54. Dompmartin A, Boon LM, Labbe D. Infantile hemangiomas: differential diagnosis and associated anomalies. Ann Chir Plast Esthet. 2006;51:300-309. French.

55. Lee BB, Laredo J, Deaton DH, Neville RF. Arteriovenous malformations: evaluation and treatment. In: Gloviczki P, editor. Handbook of Venous Disorders: Guidelines of the American Venous Forum. 3rd ed. London, UK: Hodder Arnold; 2009.

56. Lee BB. Vascular surgery: cases, questions and commentaries. In: Geroulakos G, van Urk H, Hobson RW II, Calligaro K, editors Congenital Vascular Malformation. London, UK: Springer-Verlag London Ltd; 2003.

57. Nicolaides AN. Cardiovascular Disease Educational and Research Trust; European Society of Vascular Surgery; The International Angiology Scientific Activity Congress Organization; International Union of Angiology; Union Internationale de Phlebologie at the Abbaye des Vaux de Cernay. Investigation of congenital malformations. Investigation of chronic venous insufficiency: a consensus statement. France, March 5-9, 1997. Circulation. 2000;102:e126-e163:27-28.

58. Mattassi R. Diagnosis and treatment of venous malformations of the lower limbs. In: Wang ZG, Becker HM, Mishima Y, Chang J, editors. Vascular Surgery. Beijing, People's Republic of China: International Academic Publishers; 1993.
59. Rutherford RB. New approaches to the diagnosis of congenital vascular malformations. In: Belov S, Loose DA, Weber J, editors. Vascular Malformations. Volume 16. Reinbek, Germany: Einhorn-Presse Verlag; 1989.

60. Rutherford RB. Congenital vascular malformations: diagnostic evaluation. Semin Vasc Surg. 1993;6:225-232.

61. Stillo F. Diagnostics and treatment of peripheral venous malformations: state of the art. Angéiologie. 1998;50:30-40. French.

62. Gold L, Nazarian LN, Johar AS, Rao VM. Characterization of maxillofacial soft tissue vascular anomalies by ultrasound and color Doppler imaging: an adjuvant to computed tomography and magnetic resonance imaging. J Oral Maxillofac Surg. 2003;61:19-31.

63. Yoshida H, Yusa H, Ueno E. Use of Doppler color flow imaging for differential diagnosis of vascular malformations: a preliminary report. J Oral Maxillofac Surg. 1995;53:369-374.

64. Lee BB, Mattassi R, Choe YH, et al. Critical role of duplex ultrasonography for the advanced management of a venous malformation (VM). Phlebology. 2005;20:28-37.

65. Dubois J, Soulez G, Oliva VL, Berthiaume MJ, Lapierre C, Therasse E. Soft-tissue venous malformations in adult patients: imaging and therapeutic issues. Radiographics. 2001;21:1519-1531.

66. Rak KM, Yakes WF, Ray RL, et al. MR imaging of symptomatic peripheral vascular malformations. AJR Am J Roentgenol. 1992;159: 107-112.

67. Gelbert F, Riche MC, Reizine D, et al. MR imaging of head and neck vascular malformations. J Magn Reson Imaging. 1991;1:579-584.

68. Yonetsu K, Nakayama E, Miwa K, et al. Magnetic resonance imaging of oral and maxillofacial angiomas. Oral Surg Oral Med Oral Pathol. 1993;76:783-789.

69. Lee BB, Choe YH, Ahn JM, et al. The new role of MRI (magnetic resonance imaging) in the contemporary diagnosis of venous malformation: can it replace angiography? J Am Coll Surg. 2004;198: 549-558.

70. Khaled M, Elsayes KM, Menias CO, et al. Vascular malformation and hemangiomatosis syndromes: spectrum of imaging manifestations. AJR Am J Roentgenol. 2008;190:1291-1299.

71. Rubin PA, Bilyk JR, Dunya IM, Weber AL. Spiral CT of an orbital venous malformation. AJR Am J Roentgenol. 1995;16:1255-1257.

72. Rauch RF, Silverman PM, Korobkin M, et al. Computed tomography of benign angiomatous lesions of the extremities. J Comput Assist Tomogr. 1984;8:1143-1146.

73. Napoli A, Fleischmann D, Chan FP, et al. Computed tomography angiography: state-of-the-art imaging using multidetectorrow technology. J Comput Assist Tomogr. 2004;28 Suppl 1:S32-S45.

74. Lee BB, Kim BT, Choi JY, Cazaubon M. Prise en charge des malformations vasculaires congénitales (MVC) en 2003: rôle de la scintigraphy corps entier dans las surveillance évolutive. Angeiologie. 2003;55:17-26. French.

75. Lee BB, Mattassi R, Kim BT, Kim DI, Ahn JM, Choi JY. Contemporary diagnosis and management of venous and AV shunting malformation by whole body blood pool scintigraphy (WBBPS). Int Angiol. 2004;23: 355-367.

76. Hollerman JJ, Bernstein MA, Froelich JW, Schkudor G. Detection of hemangiomas using whole-body imaging with technetium-99m labeled RBCs. Clin Nucl Med. 1986;11:716-717.

77. Inoue $\mathrm{Y}$, Wakita $\mathrm{S}$, Ohtake $\mathrm{T}$, et al. Use of whole-body imaging using Tc-99 m RBC in patients with soft-tissue vascular lesions. Clin $\mathrm{Nucl}$ Med. 1996;21:958-959.

78. Lee BB, Mattassi R, Kim BT, Park JM. Advanced management of arteriovenous shunting malformation (AVM) with transarterial lung perfusion scintigraphy (TLPS) for follow-up assessment. Int Angiol. 2005;24:173-184.

79. Gloviczki P, Driscoll DJ. Klippel-Trenaunay syndrome: current management. Phlebology. 2007;22:291-298.

80. Jacob AG, Driscoll DJ, Shaughnessy WJ, Stanson AW, Clay RP, Gloviczki P. Klippel-Trenaunay syndrome: spectrum and management. Mayo Clin Proc. 1998;73:28-36. 
81. Ziyeh S, Spreer J, Rossler J, et al. Parkes Weber or Klippel-Trenaunay syndrome? Non-invasive diagnosis with MR projection angiography. Eur Radiol. 2004;14:2025-2029.

82. Choi JY, Hwang JH, Park JM, et al. Risk assessment of dermatolymphangioadenitis by lymphoscintigraphy in patients with lower extremity lymphedema. Kor J Nucl Med. 1999;33:143-151.

83. Lee BB, Bergan JJ. New clinical and laboratory staging systems to improve management of chronic lymphedema. Lymphology. 2005;38: $122-129$.

84. Lee BB, Andrade M, Bergan J, et al. Diagnosis and treatment of primary lymphedema - Consensus Document of the International Union of Phlebology, 2009. Int Angiol. 2010;29:454-470.

85. Lee BB, Laredo J. Contemporary role of lymphoscintigraphy: we can no longer afford to ignore! Phlebology. 2011;26:177-178.

86. Lee BB, Laredo J, Neville R, Mattassi R. Primary lymphedema and Klippel-Trenaunay syndrome. In: Lee BB, Bergan J, Rockson SG, editors. Lymphedema: A Concise Compendium of Theory and Practice. 1st ed. London, UK: Springer-Verlag; 2011.

87. Lee BB, Laredo J, Neville R. Reconstructive surgery for chronic lymphedema: a viable option, but. Vascular. 2011;19:195-205.

88. Lee BB, Laredo J, Neville R. Primary lymphedema as a truncular lymphatic malformation. In: Lee BB, Bergan J, Rockson SG, editors. Lymphedema: A Concise Compendium of Theory and Practice. 1st ed. London, UK: Springer-Verlag; 2011.

89. Lee BB, Villavicencio JL. Primary lymphedema and lymphatic malformation: are they the two sides of the same coin? Eur J Vasc Endovasc Surg. 2010;39:646-653.

90. Scolozzi P, Laurent F, Lombardi T, Richter M. Intraoral venous malformation presenting with multiple phleboliths. Oral Surg Oral Med Oral Pathol Oral Radiol Endod. 2003;96:197-200.

91. Trop I, Dubois J, Guibaud L, et al. Soft-tissue venous malformations in pediatric and young adult patients: diagnosis with Doppler US. Radiology. 1999;212:841-845.

92. Dompmartin A, Acher A, Thibon P, et al. Association of localized intravascular coagulopathy with venous malformations. Arch Dermatol. 2008; 144:873-877.

93. Dompmartin A, Ballieux F, Thibon P, et al. Elevated D-dimer level in the differential diagnosis of venous malformations. Arch Dermatol. 2009; 145:1239-1244.

94. Mattassi R. Differential diagnosis in congenital vascular-bone syndromes. Semin Vasc Surg. 1993;6:233-244.

95. Mattassi R, Vaghi M. Vascular bone syndrome - angi-osteodystrophy: current concepts. Phlebology. 2007;22:287-290.

96. Yakes WF, Parker SH. Diagnosis and management of vascular anomalies. Interventional Radiology, 1992;1:152-189.

97. Burrows PE, Mulliken JB, Fellows KE, Strand RD. Childhood hemangiomas and vascular malformations: angiographic differentiation. AJR Am J Roentgenol. 1983;141:483-488.
98. Mazereeuw-Hautier J, Syed S, Leisner RI, et al. Extensive venous/ lymphatic malformations causing life-threatening haematological complications. Br J Dermatol. 2007;157:558-562.

99. Hermans C, Dessomme B, Lambert C, et al. Venous malformations and coagulopathy. Ann Chir Plast Esthet. 2006;51:388-393.

100. Redondo P, Aguado L, Marquina M. Angiogenic and prothrombotic markers in extensive slow-flow vascular malformations: implications for antiangiogenic/antithrombotic strategies. Br J Dermatol. 2010;162: $350-356$.

101. Mazoyer E, Enjolras O, Bisdorff A, et al. Coagulation disorders in patients with venous malformation of limbs and trunk: a study in 118 patients. Arch Dermatol. 2008;144:861-867.

102. Kasabach HH, Merritt KK. Capillary hemangioma with extensive purpura: report of a case. Am J Dis Child. 1940;59:1063-1070.

103. Mazoyer E, Enjolras O, Laurian C, et al. Coagulation abnormalities associated with extensive venous malformations of the limbs: differentiation from Kasabach-Merritt syndrome. Clin Lab Haematol. 2002;24:243-251.

104. Sarkar M, Mulliken JB, Kozakewich HPW, et al. Thrombocytopaenic coagulopathy (Kasabach-Merritt phenomenon) is associated with Kaposiform hemangioendothelioma and not with common infantile hemangioma. Plast Reconstr Surg. 1997;100:1377-1386.

105. Hall GW. Kasabach-Merritt syndrome: pathogenesis and management. Br J Haematol. 2001;112:851-862.

106. Levi M. Current understanding of disseminated intravascular coagulation. Br J Haematol. 2004;124:567-576.

107. Oduber CE, Gerdes VE, Van der Horst CM, et al. Vascular malformations as underlying cause of chronic thromboembolism and pulmonary hypertension. J Plast Reconstr Aesthet Surg. 2009;62:684-689.

108. Rodriguez-Manero M, Aguado L, Redondo P. Pulmonary arterial hypertension in patients with slow-flow vascular malformations (extensive venous malformations or Klippel-Trenaunay syndrome). Arch Dermatol. 2010;146:1347-1352.

109. Redondo P. The hidden face of venous malformations. Arch Dermatol. 2008;144:922-925.

110. Enjolras O, Mulliken JB, Boon LM, Wassef M, Kozakewich HP, Burrows PE. Noninvoluting congenital hemangioma: a rare cutaneous vascular anomaly. Plastic and Reconstructive Surgery. 2001.

111. North PE, Waner M, James CJ, Mizeracki A, Frieden IJ, and Mihm MC, Jr. Congenital nonprogressive hemangioma: a distinct clinicopathological entity unlike infantile hemangioma. Arch Dermatol. 137: 1607-1620, 2001.

112. Stein JA, Heidary N, Pulitzer M, J Schaffer JV, North P. Noninvoluting congenital hemangioma. Dermatol Online J. 2013;14:7.
Journal of Vascular Diagnostics

\section{Publish your work in this journal}

Journal of Vascular Diagnostics is an international, peer-reviewed journal of diagnostics, focusing on non invasive vascular investigation methods involved in the evaluation of vascular diseases. The journal is committed to the rapid publication in the fields of vascular diseases. Original research, review, case reports, expert opinion and commentaries
Dovepress

are all considered for publication. The manuscript management system is completely online and includes a very quick and fair peer-review system, which is all easy to use. Visit http://www.dovepress.com/testimonials.php to read real quotes from published authors. 